\title{
Stream Flow Response to Climate Change on Tikur Wuha Catchment, Rift Valley of Ethiopia
}

\author{
Brook Legese $^{1 *} \quad$ Alemayehu Muluneh ${ }^{2}$ \\ 1.Department of Natural Resources Management,Bule Hora University,Ethiopia \\ P.O BOX. 144, Bule Hora, Ethiopia \\ 2.School of Biosystem and Environmental Enginering, Hawassa University, \\ P.O. BOX. 05, Hawassa, Ethiopia
}

\begin{abstract}
Climate changes alter regional hydrologic conditions and results in a variety of impacts on water resource systems. This study aims to assess the streamflow response to Climate Change: the case of Tikur Wuha Sub-watershed, Rift Valley Basin of Ethiopia. In the study, the daily hydro-meteorological data values for the baseline period of 19812005 were used. Historical Representative Concentration Pathway (RCPs) data along with observed data of precipitation and temperature were used for extraction and bias correction using CMhyd tool. After evaluation of bias correction methods using RMSE, MAE and RE, the downscaled climate data such as, RCP4.5 and RCP8.5 scenarios was used for the future period assessment. Soil water assessment tool (SWAT) model were used to assess the streamflow response to Climate Change. The model calibration and validation results, using SWATCUP(SUFI-2), shows a good agreement with the observed flow with the coefficient of determination 0.79 and 8.6, and a Nash Sutcliffe efficiency was 0.56 and 0.64 , respectively. The dynamically downscaled daily climate variables (precipitation and temperature) were used to simulate future projections of streamflow. Streamflow projections for future time periods showed that mean annual streamflow may increase by $15.43,23.48$, and $25.42 \%$ in 2020s, 2050s, and 2080s, respectively, from the baseline period for RCP 4.5 scenario, whereas for RCP 8.5 scenario, it will be expect to increase by $29.58,34.20$, and $38.72 \%$ in $2020 \mathrm{~s}, 2050 \mathrm{~s}$, and $2080 \mathrm{~s}$, respectively. The model simulations considered only future climate change scenarios assuming all spatial data constant. Therefore, future study need to consider impact of land use/cover change on the sub-watershed for future sustainable development plan.
\end{abstract}

Keywords: Climate Change, Streamflow, RCPs, Bias Correction, CMhyd, SWAT, SWAT-CUP

DOI: $10.7176 /$ JEES/9-8-01

Publication date: August $31^{\text {st }} 2019$

\section{Introduction}

The Intergovernmental Panel on Climate Change (IPCC) fifth assessment report has shown an increase of $0.85^{\circ} \mathrm{C}$ in the global mean temperature since 1880 until 2012 (Kaufmann et al., 2002)(Stocker, T. ed., 2014). These changes in global temperature have been accompanied by changes in climate in different ways (Feng et al., 2014)(Feng et al. 2014). Many regions have experienced changes in precipitation leading to the frequent occurrence of floods (Min, Zhang, \& Zwiers, 2008)(Min et al. 2008) and droughts (Dai, 2013)(Dai 2011, 2013). These changes in the climate system will have a strong impact on local and regional hydrological regimes in many regions of the world (Dibike \& Coulibaly, 2005),(Dibike and Coulibaly 2005, Hu et al. 2013). The IPCC also has projected that if greenhouse gas emissions, the leading cause of climate change, continue to rise, the mean global temperatures will increase $1.4-5.8^{\circ} \mathrm{C}$ by the end of the $21^{\text {st }}$ century(IPCC, 2007) (IPCC, 2007).

The IPCC finding indicates that developing countries, such as Ethiopia will be more vulnerable to climate change. Because of the less flexibility to adjust the economic structure and is largely dependent on agriculture, the impact of climate change has far reach implication in Ethiopia. Increased industrial activity and excessive deforestation during the last century and a half have increased the concentration of carbon dioxide in Earth's atmosphere. This has, in turn, initiated large-scale atmospheric processes resulting in a change of global temperature and precipitation (among other variables). Changes in Earth's climate system can disrupt the delicate balance of hydrologic cycle and can eventually lead to increased occurrence of extreme events (such as flood, droughts, heat waves, summer and ice storms, etc.) (Bernstein, et al, 2008).

There have been few studies performed utilizing CMIP3 GCM under SRES scenarios for climate change impact studies in Tikur Wuha Sub-Watershed. Which include a studies done by Diriba (2015) using only one GCM model(HadCM3) of the IPCC fourth assessment report(AR4); under three SRES emission scenarios (A1B, A2 \& B1) and the study concluded that the river flow will increase at the end of 2099 and had recommended further studies has to carry out using ensemble of GCM output. However, Studies performed at the regional scale, which is based on the IPCC fifth assessment report(AR5) to investigate the future changes of hydrologic regimes, and water resources availability under climate change in Tikur Wuha Sub-watershed with respect to RCPs are still limited. Therefore, studies that fill these gaps and provide information are very important. So, this research was focused on using dynamically downscaled ensemble of $20 \mathrm{GCMs}$ models. 
Hence, there is a need to quantify and assess the future scenarios of climate change and its impact on water resources of the country in general and the basin in particular, because the country's future development relies on this resource. Therefore, researching in the area of climate change on TikurWuha sub-watershed, in particular, is very vital. Hence, the objective of this study is to assess climate change impacts on stream flow in Tikur Wuha watershed for the future time, using Regional Climate Model Outputs, RCPs (4.5 and 8.5) and rainfall-runoff hydrological model SWAT.

\section{Materials and Methods}

Description of the study area

Tikur Wiha sub-watershed is part of Lake Hawassa watershed. It is located in central rift valley in central Ethiopia. It lies between $\left(6^{0} 49^{\prime}-7^{0} 11^{\prime} \mathrm{N}\right.$ and $\left.38^{\circ} 28^{\prime}-38^{0} 43^{\prime} \mathrm{E}\right)$ at $275 \mathrm{Km}$ south of Addis Ababa (Fig. 3.1). It has elevation ranging between 1680-m.a.s. 1 at the outlet of Tikurwuha River into the lake and 2940 ma.s.l at Kululu ridge South East of the sub-watershed. The only perennial river supplies water to the lake Hawassa. The sub-watershed is accessible through Addis-Moyale road at Westside, Shashemane-Wondo-Wondo Mazoria road at the middle and Hogiso-Guguma-Koffele road at the Eastern side of the watershed. The total area of the sub-watershed is 670.25 $\mathrm{km}^{2}$. The sub-watershed is characterize by flat-lying topography with small hills and ridges at the Escarpment.

\section{Research Design, Data Collection and Analysis}

Data collection, homogeneity test, consistence test, bias correction method evaluation, and data preparation for SWAT input have been performed. The metrological data were collected from the Ethiopian National Meteorology Agency(1980-2005) and hydrological data(1980-2005) were collected from Ministry of Water, Irrigation, Energy and Electricity of Ethiopia. Next to this, model run and calibration was done until it gives the best possible correspondence between observed and simulated stream flow. Then, model validation was performed. Finally, climate change impact on stream flow in Tikur Wuha watershed has been evaluated.

\section{Homogeneity test}

Non-homogeneous data series for climate change impact assessment may amplify real climate variations. The collected data said to be homogenous, if the measurements have been consistently done by the same method, with the same instrumentation, at the same time and place, and in the same environment. The homogeneity test was evaluated using RAINBOW software for this study by means of frequency analysis, since it is one of the methods designed to study the homogeneity of hydro-meteorological datasets. The restriction of homogeneity assures that the observations are from the same population. Tests of homogeneity is relay on the cumulative deviations from the mean using;

$\mathrm{S}_{\mathrm{K}}=\sum_{i=1}^{\boldsymbol{k}}\left(\boldsymbol{X}_{\boldsymbol{i}-\bar{X})} \ldots \mathrm{K}=1, \ldots \ldots, \mathrm{n}\right.$

Where; $\mathrm{X}_{\mathrm{i}}$ is time series data records from $\mathrm{x}_{1}, \mathrm{x}_{2}, \mathrm{x}_{3}$; and $X$ mean of the data. The initial value of $\mathrm{S}(\mathrm{k}=0)$ and last value $\mathrm{S}(\mathrm{k}=\mathrm{n})$ are equal to zero. For a homogenous record, one may expect that the $\mathrm{SK}^{\mathrm{ee}}$ s fluctuate around zero since there is no systematic pattern in the deviations of the "s from their mean value. If the cumulative deviation crosses one of the horizontal lines the homogeneity of the data set is rejected with respectively 90,95 and $99 \%$ probability. The probabilities of rejecting the homogeneity of the datasets were evaluated for this study in the Homogeneity statistics menu.

\section{Consistency test}

The consistency of time series data analyzed based on the theory that a plot of two cumulative quantities that are measured for the same time period should be a straight line and their proportionality remain unchanged, which is represented by the slope. To check the consistency of data, the double mass curve was used to correct rain gauge data for the given station. In this study station of Haisawita, Wendo Genet and Shashemane were needed slope adjustment and adjusted accordingly.

\section{RCP Bias Correction using CMhyd and performance evaluation}

Often, the downscaled RCPs data cannot be directly used for impact assessment as the computed variables may differ systematically from the observed one. Bias correction is therefore applied to compensate for any tendency to overestimate or underestimate the mean of downscaled variables, using CMhyd(Climate Model data for hydrologic modeling) software package.Bias correction is all about identifying the biases between the observed and simulated historical climate variables to parameterize a bias correction algorithm for the simulated historical climate data.

The correction algorithm and its parameterization for current climate conditions were assumed valid for future conditions as well (Fig. 3.9). In CMhyd, there are about eight bias correction methods. Among these methods, based on (Teutschbein \& Seibert, 2012)(Teutschbein and Seibert, 2010, 2012) recommendation this study was used the distribution mapping and variance scaling for the precipitation and temperature bias correction of RCPs 
data, respectively.

The performance of the bias correction method should be evaluated using the root means square error (RMSE), the mean absolute error (MAE) and the Relative Error (RE) (Shamarokh A, 2012). These was calculated using the following equations;

$$
\begin{aligned}
& \text { RMSE }=\sqrt{\frac{\left.\sum_{i}^{N}\left(Y_{S}-Y_{o}\right)\right)^{2}}{N}} \\
& \mathrm{MAE}=1 / N_{N} \sum_{i=1}^{N}\left|Y_{S}-Y_{o}\right| \\
& \mathrm{RE}=\frac{1 /{ }_{N} \sum_{i=1}^{N}\left(Y_{S}-Y_{O}\right)}{Y_{\text {mean }}}
\end{aligned}
$$

Where $\mathbf{Y}_{\mathbf{o}}$ is the observed value at time step i, $\mathbf{Y}_{\mathbf{s}}$ is simulated value at time step i, $\mathbf{Y}_{\text {mean }}$ is the mean of observed values, and $\mathbf{N}$ is the number of observations.

\section{Data preparation for SWAT model inputs}

SWAT model requires observed daily input data of rainfall, air temperature, relative humidity, wind speed, sunshine hour(that have been converted into solar radiation), stream flow (for calibration and validation) and catchment characteristics of the study area. The average areal rainfall was estimated by multiplying the rainfall amount of each station with its area of polygon and the sum of these products was divided by the total area of the basin (i.e., Thiessen polygon involves by assigning relative weights to the rainfall stations to compute the areal depth of rainfall over the study area).

\section{The soil and water assessment tool hydrological model}

For this study, Soil and Water Assessment Tool (SWAT) hydrological model was used. It is a physically based semi-distributed geospatial hydrologic model. It operates as an extension within ArcGIS 10 and it requires data in GIS formats. The model uses remote sensed and ground observation data (soil, land cover, rainfall and temperature) and digital elevation data (DEM) sets describing the land surface to calculate the basin hydrologic water cycle. It provides a continuous simulation of stream flow, on a daily time step. The model consists of two parts: a GISbased component used for model data input preparation, and the rainfall-runoff processing component.

SWAT simulates precipitation, run-off and routing processes, both natural and controlled. This study currently focused on application of watershed model (SWAT) for Tikur Wuha catchments to establish rainfallrunoff modeling for the determination of important hydrologic parameter runoff volume in order to use them for climate change impact quantification and for further water resource development works. It has been designed to be applicable in a wide range of geographic areas for solving the widest possible range of problems.

\section{Hydrologic response units}

The Hydrologic Response Units (HRU) has been defined in ArcSWAT by overlaying soils, land use and slope classes. These overlay land use classes, soil units and slope classes in a sub-catchment were taken into account, which were larger than the respective threshold value. As the SWAT manual recommends, the study was considered four classes of slope, $0-5 \%, 5-10 \%, 10-15 \%$ and $\geq 15 \%$ (Fig. 3.14). The multiple HRU definition criteria were then performed for most applications the default settings for land use threshold (20\%) and soil threshold $(10 \%)$ and slope threshold (20\%) for individual sub-basin area (Arnold et al., 2012)(ArcSWAT, 2012). Overall, there were around 128 HRUs defined in the entire Tikur Wuha watershed within 27 sub-basin.

Surface runoff occurs, whenever the rate of water application to the ground surface exceeds the rate of infiltration, i.e. it is the excess water that cannot anymore infiltrate into the ground. Because of this process, the correct estimation of the infiltration is crucial for the subsequent evaluation of the surface runoff. SWAT provides two infiltration methods for estimating the surface runoff volume component from HRUs, namely, the SCS-curve number $(\mathrm{CN})$ and the Green and Ampt infiltration method. While the $\mathrm{CN}$-method uses daily rainfall rates, the Green \& Ampt technique requires smaller time-steps to properly simulate the infiltration process. In the present study, SCS-curve number method was used to estimate runoff.

Here the surface runoff is modeled in SWAT using the SCS curve number method, i.e.,

$Q_{\text {surf }}=\frac{\left(R_{\text {day }}-I_{a}\right)^{2}}{\left(R_{\text {day }}-I_{a}+S\right)}$

Where: Qsurf, accumulated runoff or rainfall excess $\left(\mathrm{mm} \mathrm{H}_{2} 0\right)$, $\mathbf{R}_{\text {day }}$, rainfall depth for the day $\left(\mathrm{mm}_{2} 0\right)$, $\mathbf{I}_{\text {a, }}$ initial abstractions which includes surface storage, interception and infiltration, prior to runoff $\left(\mathrm{mm} \mathrm{H}_{2} \mathrm{O}\right)$ and which is usually taken as equal to $0.2 \mathrm{~S}$, with $\mathbf{S}$, retention parameter $\left(\mathrm{mm} \mathrm{H}_{2} 0\right)$

The retention parameter $\mathrm{S}$ is defined by: 


$$
S=25.04\left[\frac{1000}{C N}-10\right]
$$

Where; $\mathrm{CN}$ is the SCS-curve number, which ranges from 0 to 100

\section{SWAT model calibration, validation and performance evaluation}

Next to simulation; SWAT model calibration was followed for this study. The SWAT model calibration is a set of parameters adjustment to provide the best possible correspondence between recorded and simulated flow from a catchment. In this study, the SWAT model calibration and validation were performed using automated calibration and validation developed in SWAT Calibration and Uncertainty Program (SWAT-CUP). Sequential Uncertainty Fitting version 2 (SUFI-2) algorithms was selected in SWAT-CUP that finds out the most favorable model parameters within the uncertainty ranges of $95 \%$ after incorporating the possible parameters ranges. The streamflow data from 1992-2001 was used for calibration.

Curve number parameter, soil parameter, and slope parameters are used for calibration in SWAT model. The model performance should be evaluated before it receives any application. In this study the model performance was evaluate through a set of objective functions that measure the goodness-of-fit between simulated and observed hydrograph.

For this study, model simulation has been evaluated using efficiency criteria such as Nash and Sutcliffe simulation efficiency (NSE), coefficient of determination (R2), and PBIAS. In general, NSE and R2 were used to evaluate the model ability to reproduce the pattern of the observed hydrograph. The PBIAS was used to quantify the error between observed and simulated stream flow.

The coefficient of determination R2, Nash-Sutcliffe coefficient of efficiency (NSE), and PBIAS were estimated by:

$\boldsymbol{R}^{2}=\left(\frac{\sum_{i=1}^{n}\left(\boldsymbol{Q}_{o b s}-\overline{\mathbf{Q}}_{o b s}\right)^{2}-\sum\left(\boldsymbol{Q}_{\text {sim }}-\overline{\mathbf{Q}}_{\text {sim }}\right)^{2}}{\sum\left(\boldsymbol{Q}_{o b s}-\boldsymbol{Q}_{\text {sim }}\right)^{2}}\right)$

Where; $\mathrm{Q}_{\mathrm{obs}}=$ observed discharge, $\mathrm{Q}_{\text {sim }}=$ Simulated discharge, ${ }^{-}{ }_{\mathrm{obs}}=$ mean of observed discharge, ${ }^{-}{ }_{\text {sim }}=$ mean of simulated discharge

$\mathrm{R}^{2}$ indicates how the simulated data value correlated to the observed data. The range of $\mathrm{R}^{2}$ extends from 0 (unacceptable) to 1 (best).

$\boldsymbol{E}_{N S}=1-\frac{\sum\left(\boldsymbol{Q}_{o b s}-\boldsymbol{Q}_{\text {sim }}\right)^{2}}{\sum\left(\boldsymbol{Q}_{o b s}-\bar{Q}_{\text {obs }}\right)}$

Where; $\mathrm{Q}_{\mathrm{obs}}=$ observed discharge, $\mathrm{Q}_{\text {sim }}=$ simulated discharge, ${ }_{\text {obs }}=$ mean of observed discharge

Nash-Sutcliffe efficiency can range from $-\infty$ to 1 .an efficiency of $E_{N S}=1$ Corresponding to a perfect match of modeled discharge to the observed data. The closer the model results to 1 the more accurate the model is.

PBIAS $=\frac{\sum\left(Q_{\text {obs }}-Q_{\text {sim }}\right)}{\sum Q_{\text {obs }}} * 100$

Where: $Q s_{i m}$ is the simulated value, $Q_{o b s}$ is the observed value

A value close to $0 \%$ is best for PBIAS. A negative value indicates model overestimation and a positive value indicate model underestimation.

\section{Results and Discussions}

RCPs Bias Correction

In this study, the bias correction method was applied to correct systematic bias of raw climatic variables: precipitation for four meteorological stations (Hawassa, Shashemene, Wendo Genet and Haisawita), and maximum and minimum temperature for Hawassa station.

The results of the bias correction methods were evaluated using residual plots (the difference between the simulated and observed values) of precipitation and temperature in terms of mean. Furthermore, Standard model performance statistics tests were carried out by computing the root mean square error (RMSE), the mean absolute error (MAE) and the relative error (RE). The result obtained for historical period from both residual plot and performance statistical test was discussed briefly in the sections here below.

\section{Precipitation}

A significant improvement was achieved by applying bias correction method on RCPs since the bias-corrected results provided smaller monthly mean bias values than the raw RCPs results (Fig. 4.1). In other words, the biascorrected results are closer to the observed values than the raw RCPs results at the four stations.

The mean monthly residuals of raw precipitation at Hawassa station was between $-90.78 \mathrm{~mm}$ and $-18.63 \mathrm{~mm}$ and after bias correction, the residuals was between $-16.25 \mathrm{~mm}$ and $+9.28 \mathrm{~mm}$ (Fig. 4.1a). The mean monthly residuals of raw precipitation at Haiswaita station was between -62.56 and $319.07 \mathrm{~mm}$ and after bias correction, the residuals was between $-10.13 \mathrm{~mm}$ and $+28.93 \mathrm{~mm}$ (Fig. $4.1 \mathrm{~b}$ ). The mean monthly residuals of raw precipitation at Shashemene station was between $-57.76 \mathrm{~mm}$ and $+295.21 \mathrm{~mm}$ and after bias correction, the residuals is between 
$-14.45 \mathrm{~mm}$ and $+11.25 \mathrm{~mm}$ (Fig. 4.1c).The mean monthly residual of raw precipitation at Wendo Genete station was between $-78.62 \mathrm{~mm}$ and $+272.03 \mathrm{~mm}$ and after bias correction, the residual was between $-34.70 \mathrm{~mm}$ and $7.68 \mathrm{~mm}$ (Fig.4.1d). These results showed that significant improvement was achieved after bias correction.

\section{Maximum and Minimum Temperature}

The bias-corrected mean monthly maximum temperature and a minimum temperature of Hawassa station was compared with the raw mean monthly maximum temperature and minimum temperature using residual plots (Fig. 4.2).

It was found that while the raw mean daily maximum temperature residuals are between $-5.3^{\circ} \mathrm{C}$ and $-1.46^{\circ} \mathrm{C}$, after bias correction the range is between $-0.39^{\circ} \mathrm{C}$ and $+0.06^{\circ} \mathrm{C}$ in terms of mean (Fig 4.2a), whereas the mean monthly residual plots of raw mean monthly minimum temperature residual were between $-2.09^{\circ} \mathrm{C}$ and $+1.86^{\circ} \mathrm{C}$, after bias correction the range was between $-0.14^{\circ} \mathrm{C}$ and $+0.24^{\circ} \mathrm{C}$ in terms of mean (Fig $4.2 \mathrm{~b}$ ).

The bias-corrected results show that the corrected RCPs provided fewer errors than the raw RCP results. Moreover, it can be seen that the models' performance statistics (RMSE, MAE, and RE) for precipitation, maximum temperature, and minimum temperature was good (Table 4.1).

\section{SWAT Model Results}

Sensitivity analysis

Sensitivity analysis is a technique of identifying the responsiveness of different parameters involving in the simulation of a hydrological process. For big hydrological models like SWAT, which involves a wide range of data and parameters in the simulation process, calibration is quite a cumbersome task. Hence, sensitivity analysis is a method of minimizing the number of parameters to be used in the calibration step by making use of the most sensitive parameters largely controlling the behavior of the simulated process. This appreciably eases the overall calibration and validation process as well as reduces the time required for it.

Before running the calibration, the sensitivity of the parameters was carried out using the Latin hypercube one-factor-at-a-time (LH-OAT) method of SWAT (van Griensven et al., 2006)(van Griensven et al.,2006). This approach combines the advantages of global and local sensitivity analysis methods and can efficiently provide a rank ordering of parameter importance. The sensitivity analysis was performed on twenty-five SWAT model parameters that may have the potential effect on the flow of the River (Fig 4.8). The ranges of parameters variation was based on the SWAT manual (Arnold et al., 2012)(Abbaspour et al, 2004). After sensitivity analysis more sensitive SWAT parameters are identified based on their p-value of statistical significance for the catchment. After setting up the SWAT-CUP using SWAT model outputs and incorporating all input parameters, simulations were carried out with SUFI-2 by running 500 simulations and the Sensitivity analysis was done for both the calibration and warming up periods (1989-2001).

Among twenty-five parameters used for the sensitivity analysis, only eleven of them revealed meaningful effect on the monthly flow simulation of the Tikur Wuha River. Curve number (CNII), soil bulk density (SOLBD), soil hydraulic conductivity (SOL-K), available water capacity (SOL AWC), Depth from soil surface to bottom of layer (SOL-Z), soil evaporation compensation factor(ESCO), Channel effective hydraulic conductivity (CH_K2), Biological mixing efficiency (BIOMIX), Manning's " $n$ " value for the main channel (CH-N2), Average slope steepness (HRU-SLP) were relatively high sensitive parameters that significantly affect surface runoff while Groundwater delay (GW_DELAY) and base flow Alpha factor (ALPHA_BF) were other parameters that mainly influence base flow. The selected sensitive parameters with their fitted value are shown in Table 4.5.In the Fig.4.8 the p-value determines the significance of the sensitivity. A value closer to zero denotes more significance.

\section{Calibration and Uncertainty Analysis}

Flow calibration was performed for a period of ten years from January 1, 1992 to December 31, 2001 using the sensitive parameters identified. However, flow was simulated for seventeen years from January 1, 1989 to December 31, 2005, within which the first three years was considered as a warm up period. Flow validation was performed for a period of four years from January 1, 2002 to December 31, 2005.

The parameters were allowed to vary during the calibration process within acceptable ranges until an acceptable fit between the measured and simulated values was obtained; no changes were made to the calibrated parameters during the 4-year of validation. Hydrologic calibration parameters and their fitted values for the gauged stations are shown in Table 4.5.

The calibration and validation results for the gauged station in Table 4.6 shows that there is a good agreement between the monthly simulated and observed flows. The general performance rating of recommended statistics for monthly time step as suggested by (Moriasi et al,2007) indicates $\mathrm{R}^{2}>0.6$, and $\mathrm{E}_{\mathrm{NS}}>0.5$, and $\mathrm{PBIAS}<\underline{+25}$ suggested by (Gupta, Soroosh, \& Patrice Ogou, 1999)Gupta et al. (1999). Based on these recommendation, the present result shows acceptable performance. 
Hence, it is observed that SWAT exhibited a satisfactory performance in representing the hydrological conditions of the Sub-Watershed. It can be seen from the flow hydrographs (Fig. 4.9 and 4.11) that the simulated flows well matched the observed flows except for peak values in the calibration period and low values in the validation period for monthly time steps.

Uncertainty analysis was also done using SWAT-CUP linked to SUFI-2 on measured stream flow data. The degree to which all uncertainties are accounted for is quantified by a measure referred to as the P-factor, which is the percentage of measured data bracketed by the $95 \%$ prediction uncertainty (95PPU) and another measure quantifying the strength of a calibration/uncertainty analysis is the R-factor, which is the average thickness of the 95PPU band divided by the standard deviation of the measured data. The results of P-factor and R-factor for monthly discharge are also shown in Table 4.6.

factor) and the thickness of the 95PPU (R-factor) had a value of 1.52 during calibration, which is a good result. The smaller R-factor value, the smaller the uncertainties and the better is the calibration work. A value close to 1 is highly desirable for R-factor with a $P$-factor also close to 1 .

As seen from the calibration and the validation results, it is deduced that the model represented the hydrological characteristics of the sub-watershed at gauging station and can be used as a baseline for further analysis.

\section{Climate Change Impact on the Streamflow}

The main objective of downscaling is to generate a reliable estimation of meteorological variables corresponding to given scenario of the future climate so that these meteorological variables will be used as basis for different types of impact studies. Therefore, after calibration and validation of hydrological models with historical record, the next step is to simulate river flows in the sub-watershed corresponding to future climate conditions by using the downscaled daily precipitation and temperature in to SWAT model. Such simulation helps to identify the hydrological impacts caused by climate change.

The future climate variables that are downscaled precipitation and temperature found as an output from the RCPs and then-then corrected RCPs were given as an input to the SWAT model. Then simulation results corresponding to each of downscaling scenario time period (baseline (1981-2005), the 2020s, 2050s, and 2080s) were analyzed for all month of the year.

\section{Climate Change Impact on Monthly Streamflow}

Climate change impact on monthly streamflow was analyzed by comparing baseline river flow with the future flows for the 2020s, 2050s, and 2080s.

In the 2020s for the RCP4.5 scenarios, the streamflow may show an increment and decrement for the given months. In this period an increment up to $114.8 \%$ in the month of July will be expected. Increase in streamflow may be observed in months which showed an increase in monthly precipitation. In the 2020s for RCP 8.5 scenario, the same effect as the RCP 4.5 scenarios of 2020 s may be observed. But the increase in monthly streamflow is expected to reach up to $152.8 \%$ in the month of July.

In the 2050s for both RCP 4.5 and RCP 8.5 scenarios, the increment and decrement of streamflow will be expected. For RCP 4.5 scenarios the monthly change in streamflow may reach up to $109.42 \%$ in the month of July whereas for RCP 8.5 scenario the monthly change in streamflow may expect to reach $208.44 \%$ in the month of November.

As in the case of 2020s and 2050s, again in 2080s for both RCP4.5 and RCP8.5 scenarios an increment and decrement in streamflow may be expected in all months in the year. For RCP 4.5 scenarios the monthly change in streamflow may reach up to $140.33 \%$ in the month of July whereas for RCP 8.5 scenarios the monthly change in streamflow may be expected to reach up to $188 \%$ in the month of October. The mean monthly percentage change of streamflow under both scenarios are available on Table 4.7 and Fig. 4.13.

\section{Climate Change Impact on Seasonal and Annual Streamflow}

The impacts of climate change on the seasonal and annual streamflow are discussed so as to foresee its consequence on the socio-economic condition on Tikur wuha sub-watershed. As mentioned in the previous section, there are three seasons in the study area: Bega (October to February). Belg (March to May), Kiremt (June to September).

During Kiremt season there will be an increment in streamflow in both scenarios, the increment may reach up to $104.68 \%$ for the RCP 4.5 scenario and $133.23 \%$ for the RCP8.5 Scenario whereas during Belg season the streamflow may decrease for both scenarios up to $73.73 \%$ and $69.77 \%$ in RCP4.5 and RCP8.5, respectively. During Bega except the decrement in 2020s which may reach up to $21.67 \%$ and $15.52 \%$ for both RCP 4.5 and RCP 8.5 scenarios respectively, there might be an increment in streamflow up to $45.2 \%$ and 44.79 for RCP 4.5 and RCP8.5 scenarios.

Overall, the increment in annual precipitation by $15.51 \%, 16.91 \% \& 18.27 \%$ leads to an increment in annual 
streamflow by $15.43 \%, 23.48 \%$ \& 25.42 for RCP 4.5 scenario whereas the increment in annual precipitation by $23.87 \%, 29.51 \%$ \& $33.01 \%$ leads to an increment in annual streamflow by $29.58 \%, 34.20 \%$ \& $38.72 \%$ for RCP 8.5 scenario. The Annual and Seasonal percentage change of streamflow under both scenarios are available in Table 4.8 and Fig. 4.14.

The study was in line with the previous study conducted by Diriba, 2015, had used CMIP3, estimated that there will be annual streamflow increment at the end of the century. Even though there is the difference in magnitude of change between this study and the current study, both confirmed that the streamflow of the Tikur Wuha sub-watershed will be increased for the coming 90 years. In addition, the current result was consistent with study done on Gidabo by (Shanka, 2017)Shanka, 2017, which shows in 2020s, 2050s and 2080s, the total average annual runoff in Gidabo river basin is increasing of up to 3.4\%, 2.9 and 6.8\% for HadCM3A2a and 5.1 \%, 5.6\% and $5.8 \%$ for HadCM3B2a scenarios, respectively.

The result also consistent with study done by Getahun ,2017 on Blate watershed in Rift Valley using ensemble of $20 \mathrm{GCMs}$, shows that based on the different climatic scenarios (RCP 4.5 and RCP 8.5), the simulation results indicated a range of possible hydrologic futures; mostly an increase in annual streamflow compared with the baseline is projected under all scenarios. The magnitude of increase for annual river discharge ranges from $10.34 \%$ to $42.42 \%$.

Other studies also show that in $2050 \mathrm{~s}$, mean annual streamflow is found to increase in all the scenarios. The maximum projected increase in annual discharge of $32.46 \%$ was found for GISSE2-H (RCP 4.5), whereas MIROC-ESMCHEM (RCP 8.5) and BCC-CSM1.1(RCP 8.5) showed almost same increase in projected annual discharges which are $26.89 \%$ and $26.27 \%$ consecutively. In 2080 s, the maximum projected increase in discharge of 47.44\% was found for BCC- CSM1.1 (RCP 8.5). Other scenarios give variable increase in discharge, 29.50\%, $18.96 \%, 38.82 \%$ and $13.60 \%$ increase in mean annual streamflow were found for MIROC-ESMCHEM (RCP 8.5), HADGEM2- ES (RCP 8.5), GISS-E2-H (RCP 4.5) (Alam, 2015)(Sarfaraz ,2015).

Generally, the obtained result for the Tikur Wuha Sub-Watershed depict a positive change of annual streamflow throughout the century by the ensemble of 20 GCMs which is driven by the projected increase in precipitation. As Tikur Wuha River is one of the tributary River feeding in to the Lake Hawassa, any change in River flow is likely to affect the Lake. The increased runoff improves water supply reliability and contributes significant inflows into the Lake Hawassa. Thus, the increased streamflow in Kiremit season may devastate flood damages and due consideration should be taken to prevent future flood hazards.

\section{Conclusions}

Climate change has potential impacts on future hydrological and meteorological variables due to increased greenhouse gas emissions, which are associated with increasing temperature of the globe. The future impact of climate change on stream flow of Tikur Wuha catchment has been studied using SWAT 2012 hydrological model, for the 2020s (2010-2039), 2050s (2040-2069) and 2080s (2070-2099) using CMIP5 projection outputs.

The bias of dynamically downscaled raw RCPs data was corrected using CMhyd tool successfully as the biascorrected climate variables produced consistent results with the historical records. The residuals between corrected and historical monthly values were smaller than the residuals between raw RCP and historical monthly values of precipitation and temperature. The bias correction methods performance evaluation for precipitation, maximum temperature, and minimum temperature was also performed and better improvement was gained after bias correction. So it can be concluding that the bias correction method used was the most accurate for downscaled climate variables to reproducing the main features of the observed data.

The Curve number, Ground water delay (GW_DELAY), and Soil bulk density (SOL-BD) showed a relatively very higher sensitivity. Soil water assessment tool (SWAT) models were well calibrated and validated using observed flow data as the coefficient of determination was above 0.6, Nash Sutcliffe efficiency index was above 0.5 and PBIAS was within $< \pm 25$ for Tikur Wuha Sub-watershed. The uncertainty analysis also showed a better result in both $\mathrm{P}$-factor and $\mathrm{R}$-factor, as the result close to one, which is recommendable.

Bias-corrected daily precipitation and temperature data of both RCP 4.5 and RCP 8.5 scenarios were used to simulate future stream flow. Streamflow projections for future time periods showed that mean annual streamflow may increase by $15.43,23.48$, and $25.42 \%$ in $2020 \mathrm{~s}, 2050 \mathrm{~s}$, and $2080 \mathrm{~s}$, respectively, from the baseline period for RCP 4.5 scenario, whereas for RCP8.5 Scenario, it will be expected to increase by $29.58,34.20$, and $38.72 \%$ for the 2020s, 2050s, and 2080s, respectively.

The result of this study confirmed that in the future mean annual streamflow will increase due to climate change at the outlet of Tikur Wuha sub-watershed that feeding the lake Hawassa. The increases in water availability will play significant benefits for small and large-scale farmers for agricultural activities, moreover, for water resources development projects. If farmers adopted themselves to cropping schedule, the climate change may contribute in a positive direction for crop water availability.

Moreover, the hydrology of Tikur Wuha River, which is the only perennial river feeds Lake Hawassa, is highly vulnerable to climate change, which causes high temporal variation of streamflow. This may need serious 
concerns for conserving ecosystem in the Lake, and food security and water resource sustainability. Therefore, adaptation strategies in and around the Tikur Wuha sub-watershed have to be developed so as to maintain the sustainability of available water resources and to prevent extreme events. Furthermore, the results presented in this study can provide valuable insight to decision makers on the degree of vulnerability of Lake Hawassa to climate change, which is important to design appropriate adaptation and mitigation strategies.

Data quality and availability should be stressed much while using distributed hydrological models. Because, the applications of SWAT model were very challenging and a lack of appropriate data was one of the biggest concerns throughout the study. Hence, without proper data, model implementation is very difficult if not impossible.

The increment of streamflow during Kiremt season may devastate flood damages and due consideration should be taken to prevent future flood hazards, through early warning.

The current study indicates that there exists a difference in the result found between SRES scenarios of previous research work and the RCPs (RCP 4.5 and RCP 8.5) in the current study. Hence, further analysis can be undertake with more RCPs and more bias correction method to give a clear picture of the result.

The model simulations considered only future climate change scenarios assuming all spatial data constant. But the change in land use scenarios and other climate variables will also have an effect on future streamflow. Therefore, a further study considering the land use/cover change would increase the confidence of result.

Finally, to link the study results to the sustainable development of the community, it is recommend using the hydrological models' outputs in water resource management models to take the socio-economic aspects of the hydrological system.

\section{Acknowledgment}

Above all, I would like to thank the almighty God for giving me the strength and wisdom to reach at this point in life.I would also like to thank the Ethiopian Ministry of Water Resources, Irrigation and Energy(MoWIE), National Meteorological Services Agency(NMSA), International Water Management Institute(IWMI) and Rift Valley office for the data and keen assistance they gave me during data collection.

\section{References}



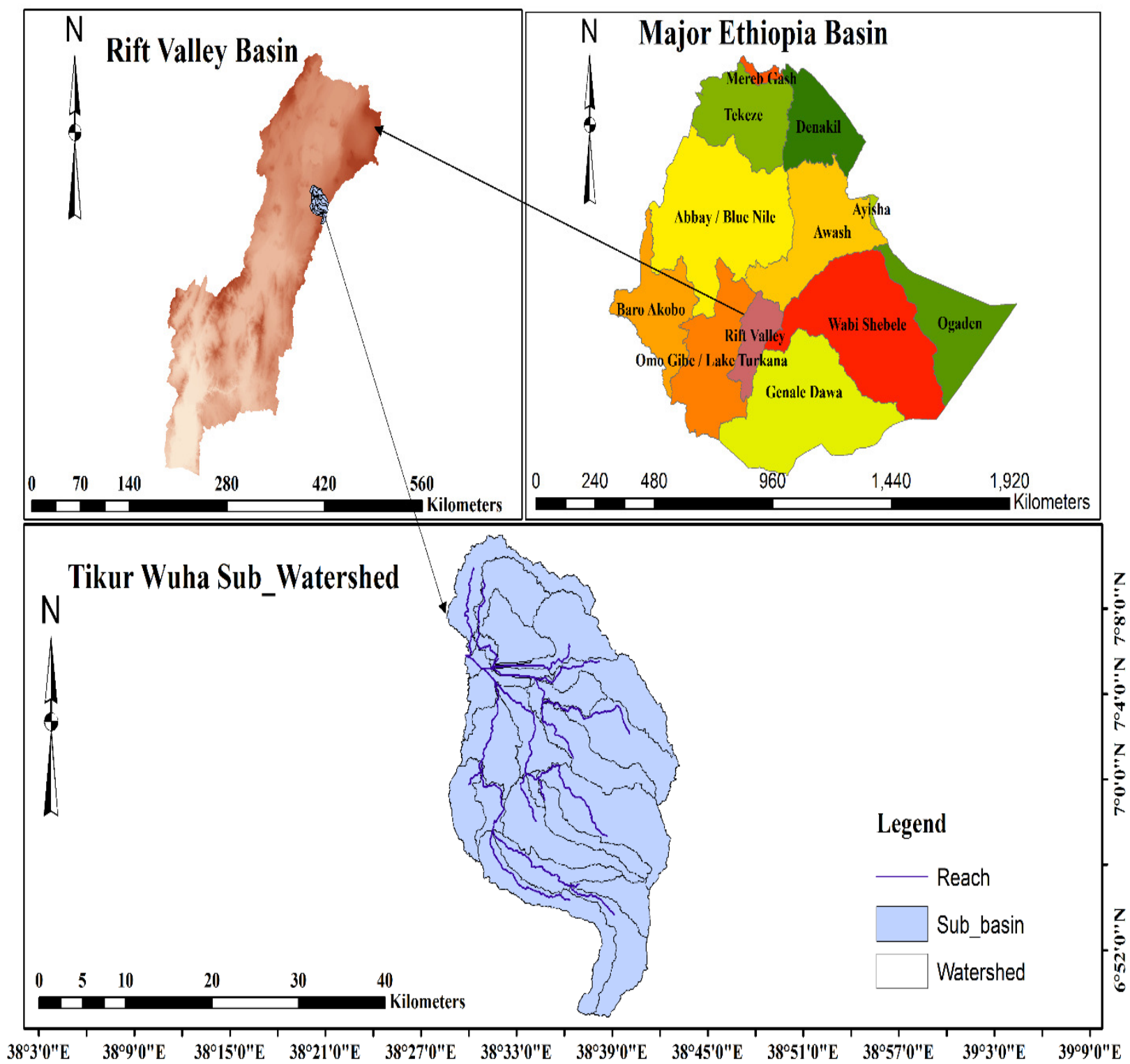

Figure 1. Map of the study area 


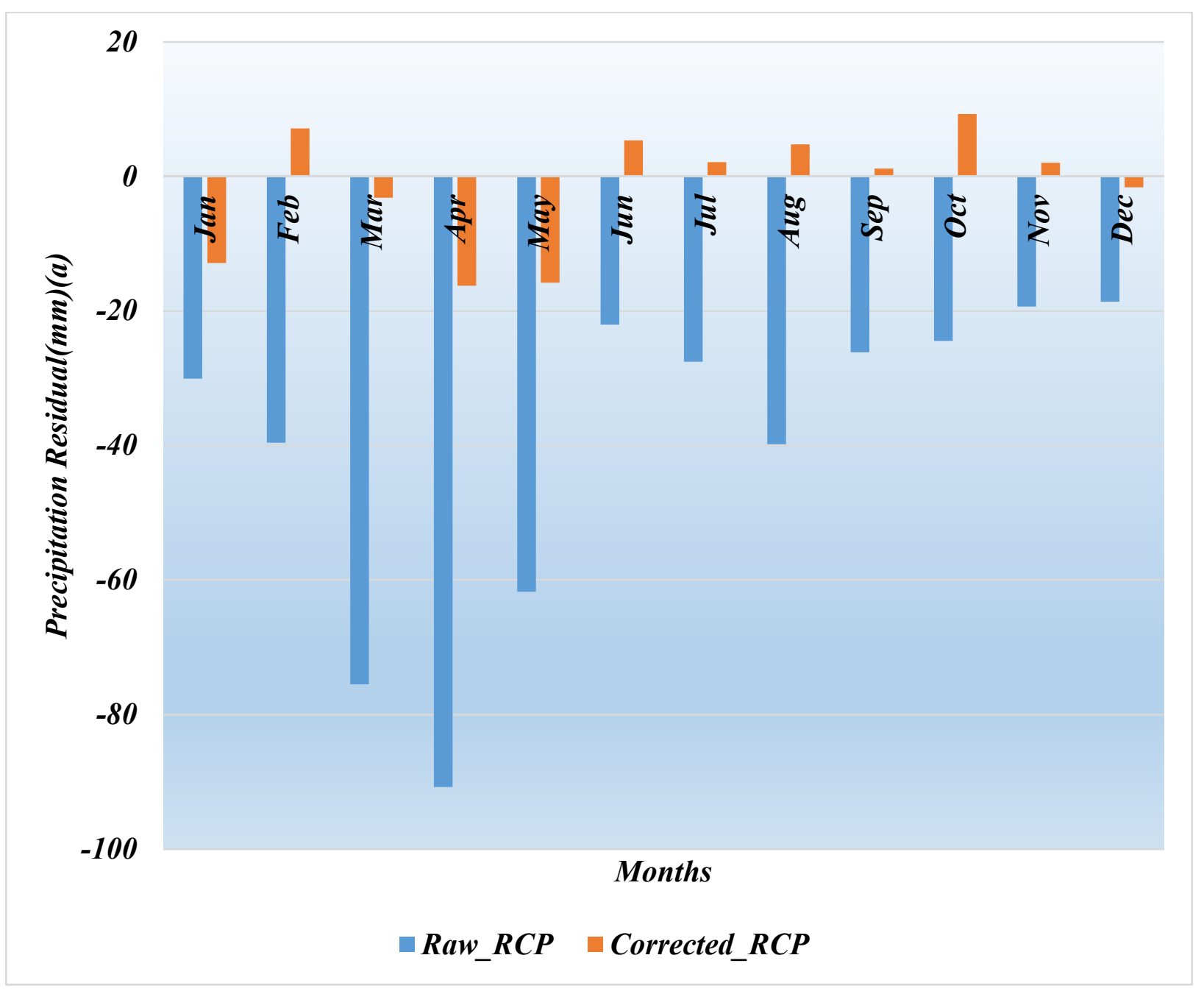




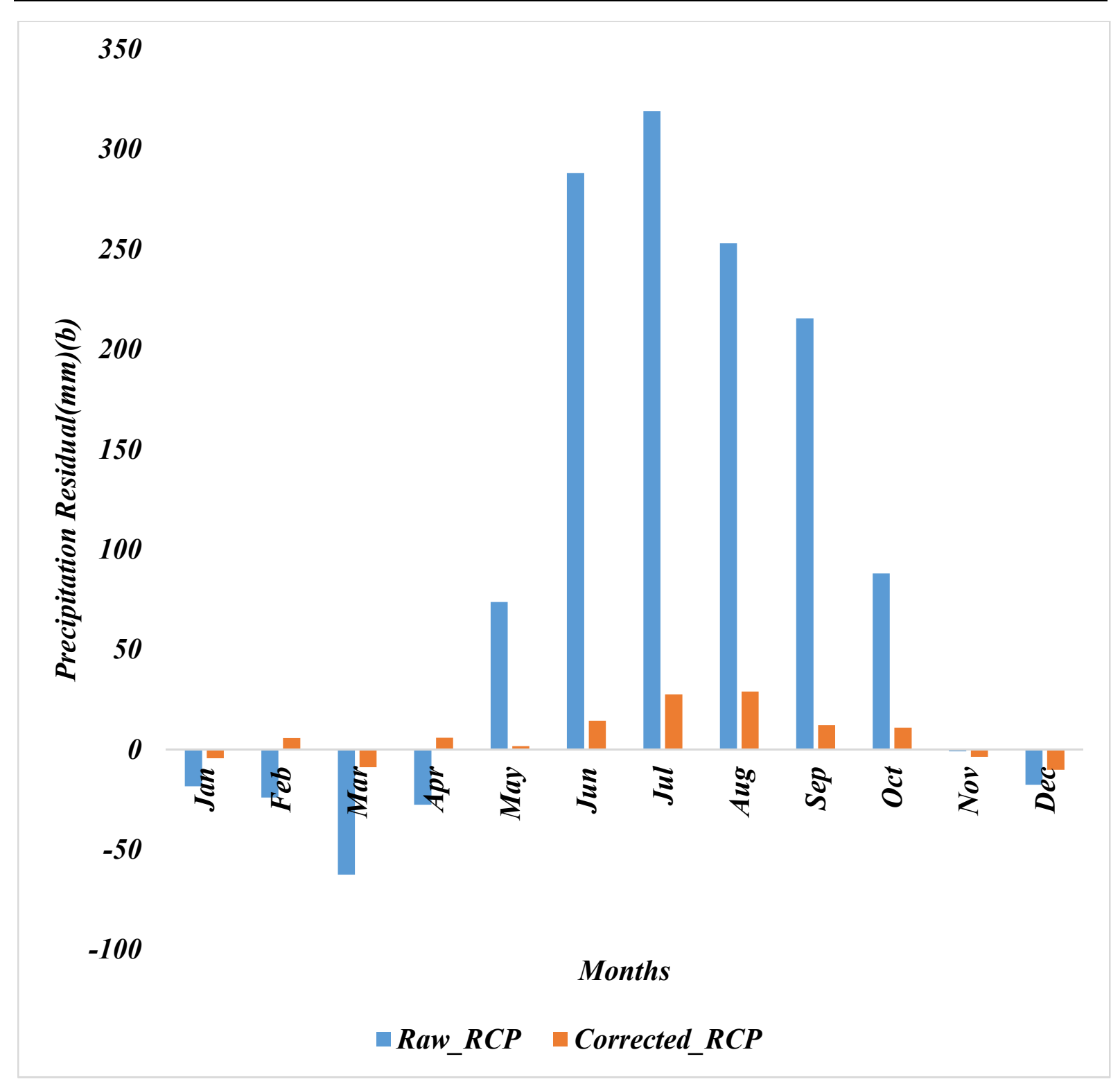




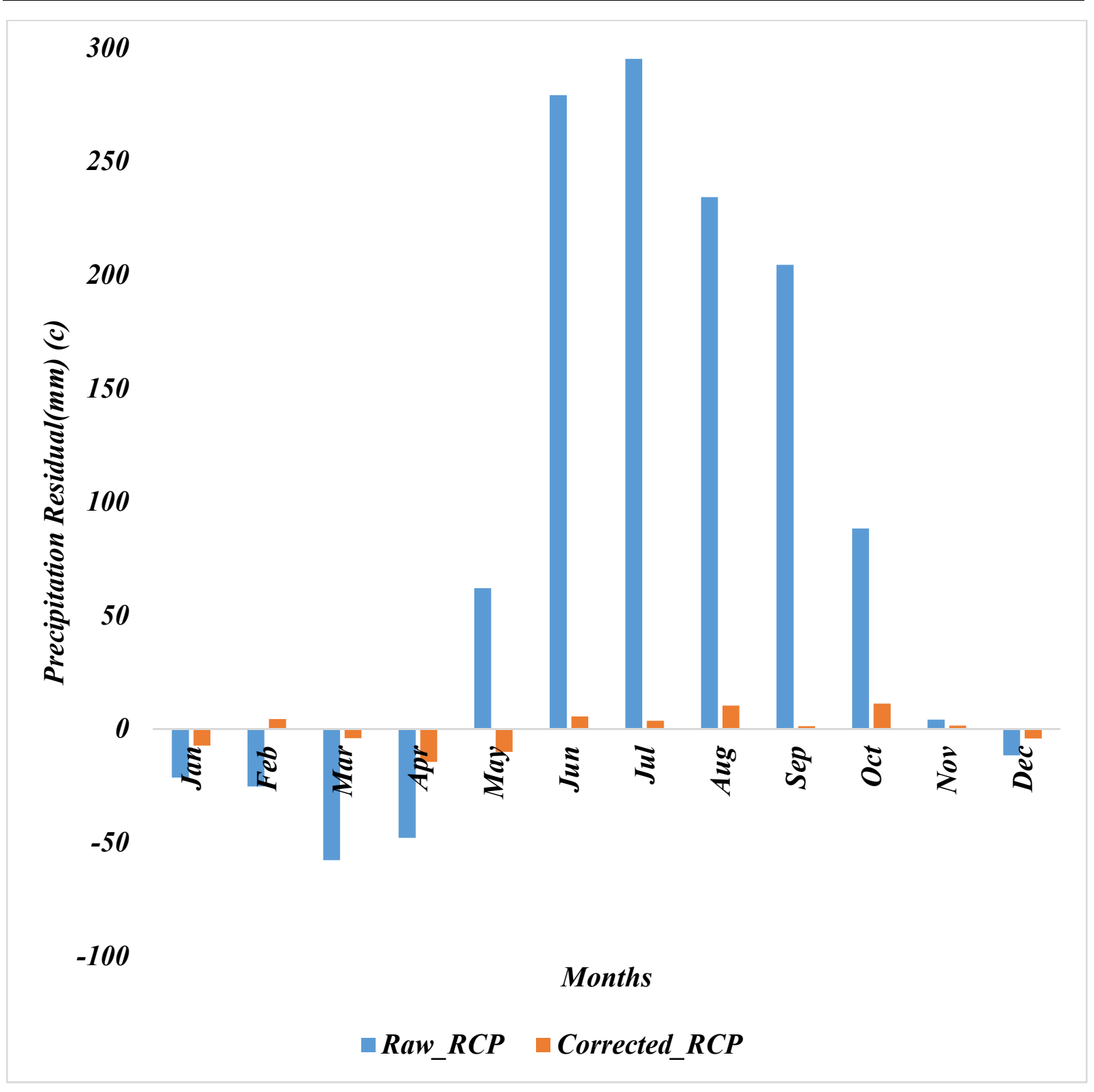




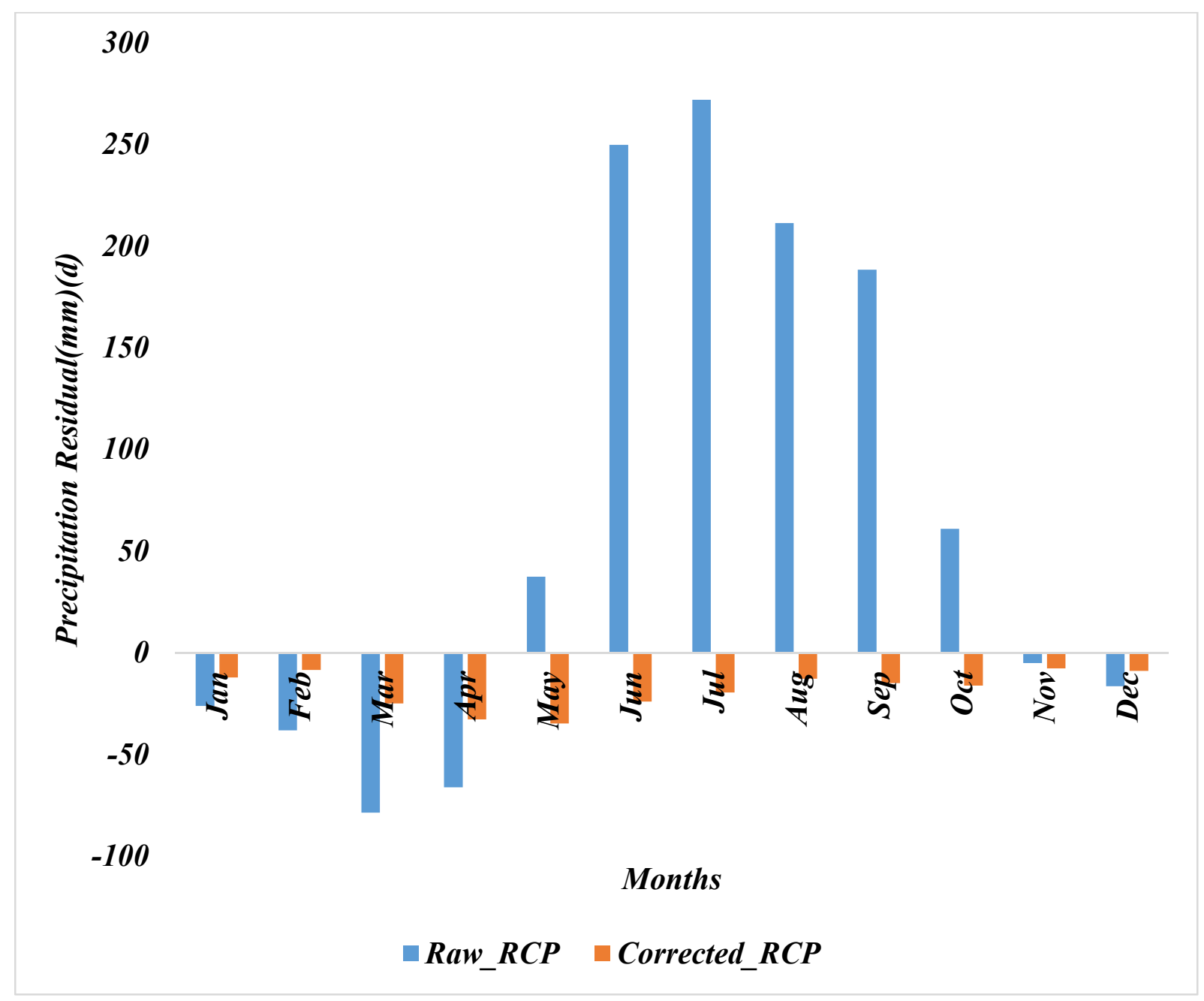

Figure 2. Mean monthly residuals plot of raw RCPs and corrected RCPs (1981-2005) for a)Hawassa b) Haisawita c)Shashemene and d)Wendo Genet stations 


\section{1}

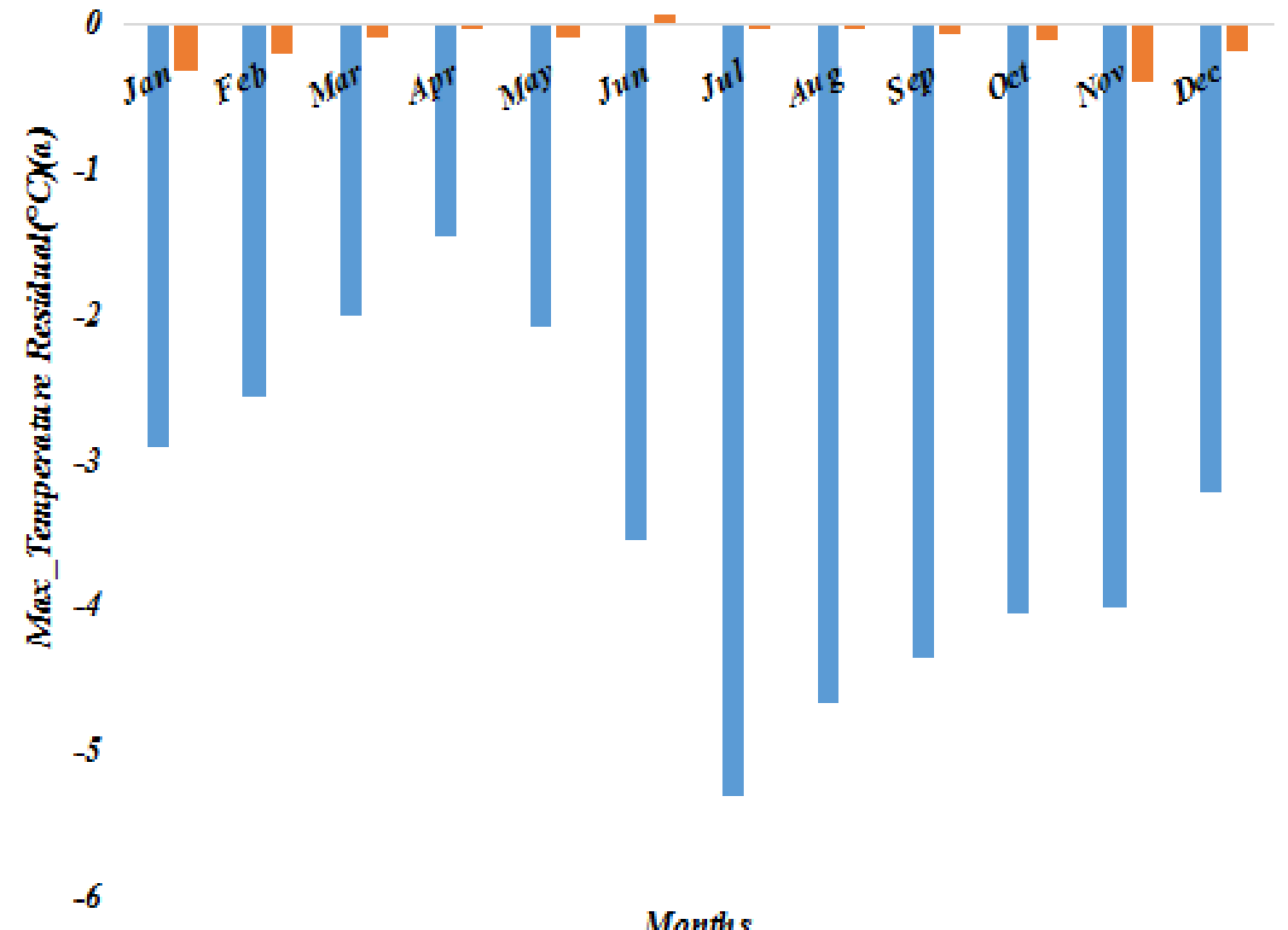

Months

Raw_RCP $₫$ Corrected_RCP 


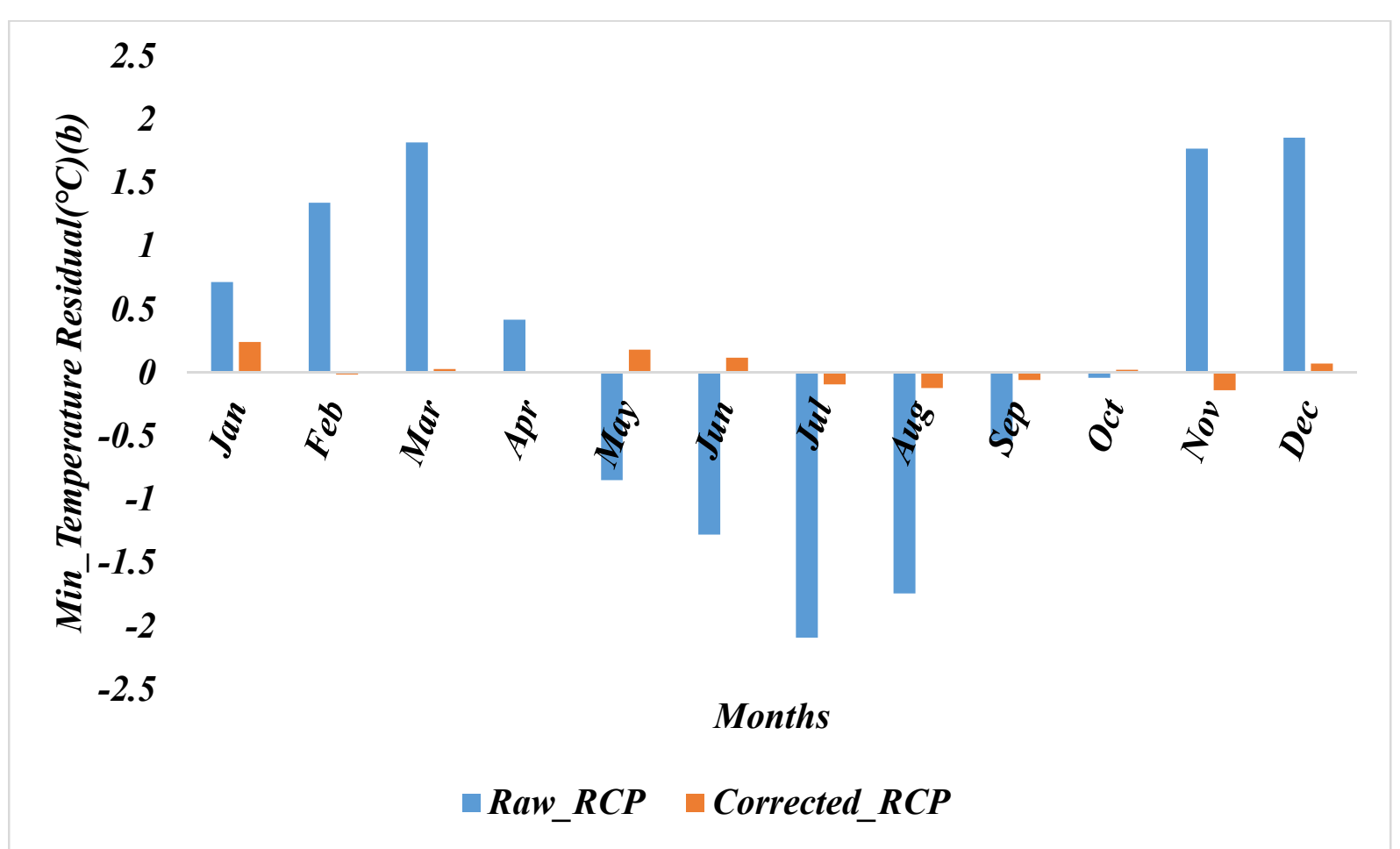

Figure 3. Mean monthly residuals temperature of raw RCPs and corrected RCPs (1981-2005) for Hawassa station a) Maximum Temperature and b) Minimum Temperature

Table 1. Performance statistical test of bias correction method

\begin{tabular}{|l|l|l|l|c|c|c|c|}
\hline \multirow{2}{*}{ Station } & Evaluation & \multicolumn{2}{|c|}{ Precipitation } & \multicolumn{2}{c|}{ Max. Temperature } & \multicolumn{2}{c|}{ Min. Temperature } \\
\cline { 3 - 8 } & & Raw & $\begin{array}{l}\text { Bias } \\
\text { corrected }\end{array}$ & Raw & $\begin{array}{l}\text { Bias } \\
\text { corrected }\end{array}$ & Raw & $\begin{array}{l}\text { Bias } \\
\text { corrected }\end{array}$ \\
\hline \multirow{4}{*}{ Hawassa } & RMSE & 45.69 & 8.61 & 3.53 & 0.17 & 1.37 & 0.12 \\
\cline { 2 - 8 } & MAE & 39.63 & 6.80 & 3.35 & 0.13 & 1.21 & 0.09 \\
\cline { 2 - 8 } & RE & -0.48 & -0.018 & -0.12 & -0.0044 & 0.01 & 0.0016 \\
\hline \multirow{5}{*}{ Shashemene } & RMSE & 152.85 & 7.62 & - & - & - & - \\
\cline { 2 - 8 } & MAE & 110.97 & 6.49 & - & - & - & - \\
\cline { 2 - 8 } & RE & 1.12 & -0.0025 & - & - & - & - \\
\hline \multirow{5}{*}{ Wendo -Genet } & RMSE & 139.84 & 20.09 & - & - & - & - \\
\cline { 2 - 8 } & MAE & 104.20 & 18.04 & - & - & - & - \\
\cline { 2 - 8 } & RE & 0.71 & -0.1949 & - & - & - & - \\
\hline
\end{tabular}




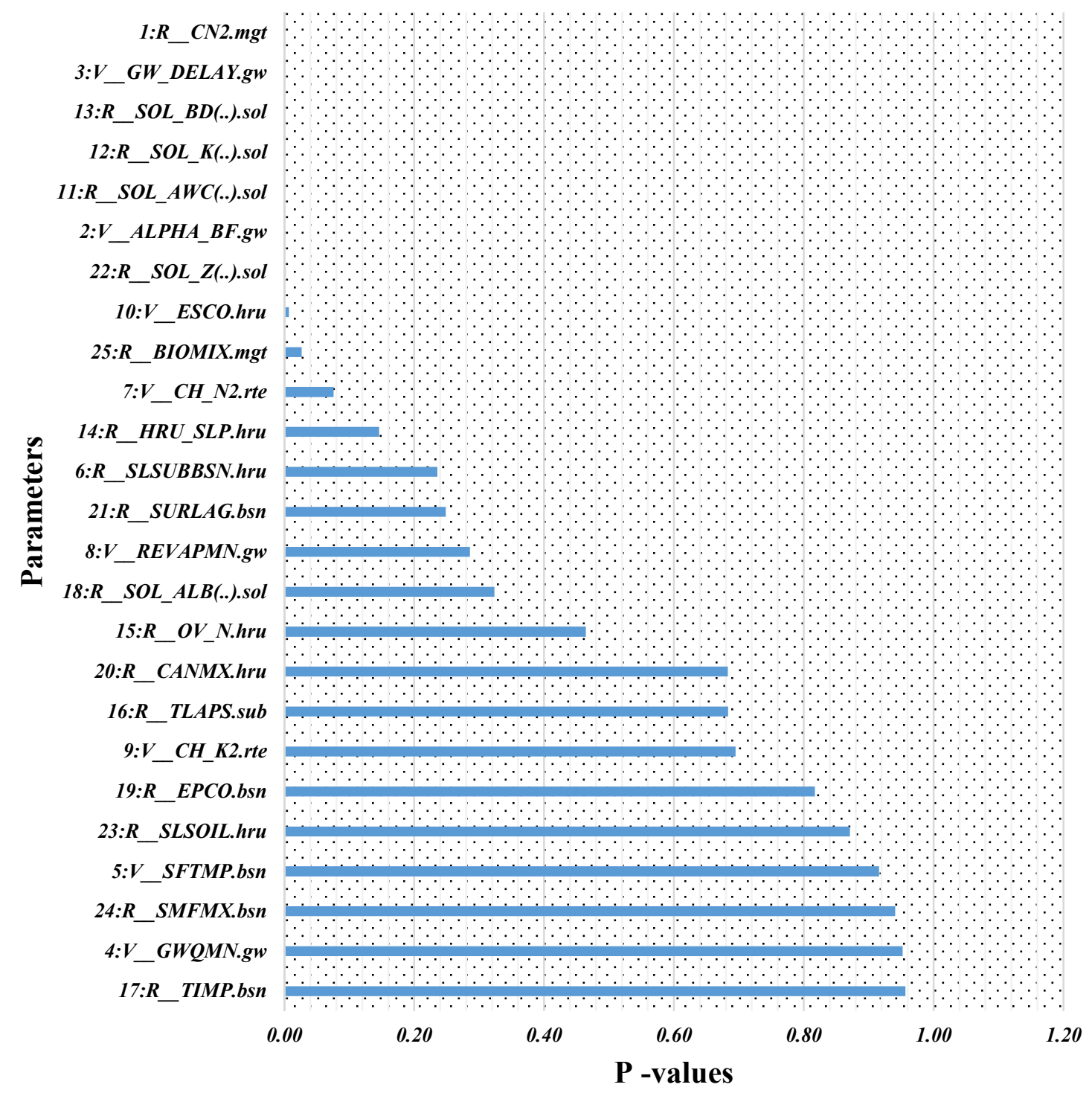

Figure 4. Global sensitivity results according to $p$-value of significance using SWAT-CUP

Table 2. Hydrologic calibration parameters values with their fitted value

\begin{tabular}{|l|l|l|l|l|}
\hline \multirow{2}{*}{ No. } & \multirow{2}{*}{ Parameter } & \multicolumn{2}{|c|}{ SWAT default } & \multirow{2}{*}{ Fitted Value } \\
\cline { 3 - 5 } & & Lower bound & Upper bound & \\
\hline 1 & r_CN2 & 35 & 98 & 35 \\
\hline 2 & V_ALPHA_BF & 0 & 1 & 0.06 \\
\hline 3 & v_GW_DELAY & 0 & 50 & 20 \\
\hline 4 & v_CH_N 2 & 0 & 1 & 0.027 \\
\hline 5 & v_ESCO & 0 & 1 & 0.68 \\
\hline 6 & r_SOL_AWC & 0 & 1 & 0.28 \\
\hline 7 & r_SOL_K & 0 & 100 & 9.97 \\
\hline 8 & r_SOL_BD & 0.9 & 2.5 & 1.07 \\
\hline 9 & r_HRU_SLP & 0 & 1 & 0.039 \\
\hline 10 & r_SOL_Z & 0 & 3000 & 130.15 \\
\hline 11 & v_BIOMIX & 0 & 1 & 0.2 \\
\hline
\end{tabular}

Note: ${ }^{r}$-sensitive parameter shows multiply by $1+$ the given fitted value.

**v-sensitive parameter shows replace the value by the given fitted value. 
Table 3. Calibration, validation and uncertainty analysis results for Tikur wuha gauged station near Hawassa Bridge

\begin{tabular}{|l|l|l|}
\hline Criteria & $\begin{array}{l}\text { Calibration } \\
(1992-2001)\end{array}$ & $\begin{array}{l}\text { Validation } \\
(2002-2005)\end{array}$ \\
\hline $\mathrm{R}^{2}$ & 0.79 & 0.86 \\
\hline ENS $_{\mathrm{NS}}$ & 0.54 & 0.64 \\
\hline PBIAS & -13.9 & -11.4 \\
\hline P-factor & 0.92 & 0.67 \\
\hline R-factor & 1.52 & 0.68 \\
\hline
\end{tabular}

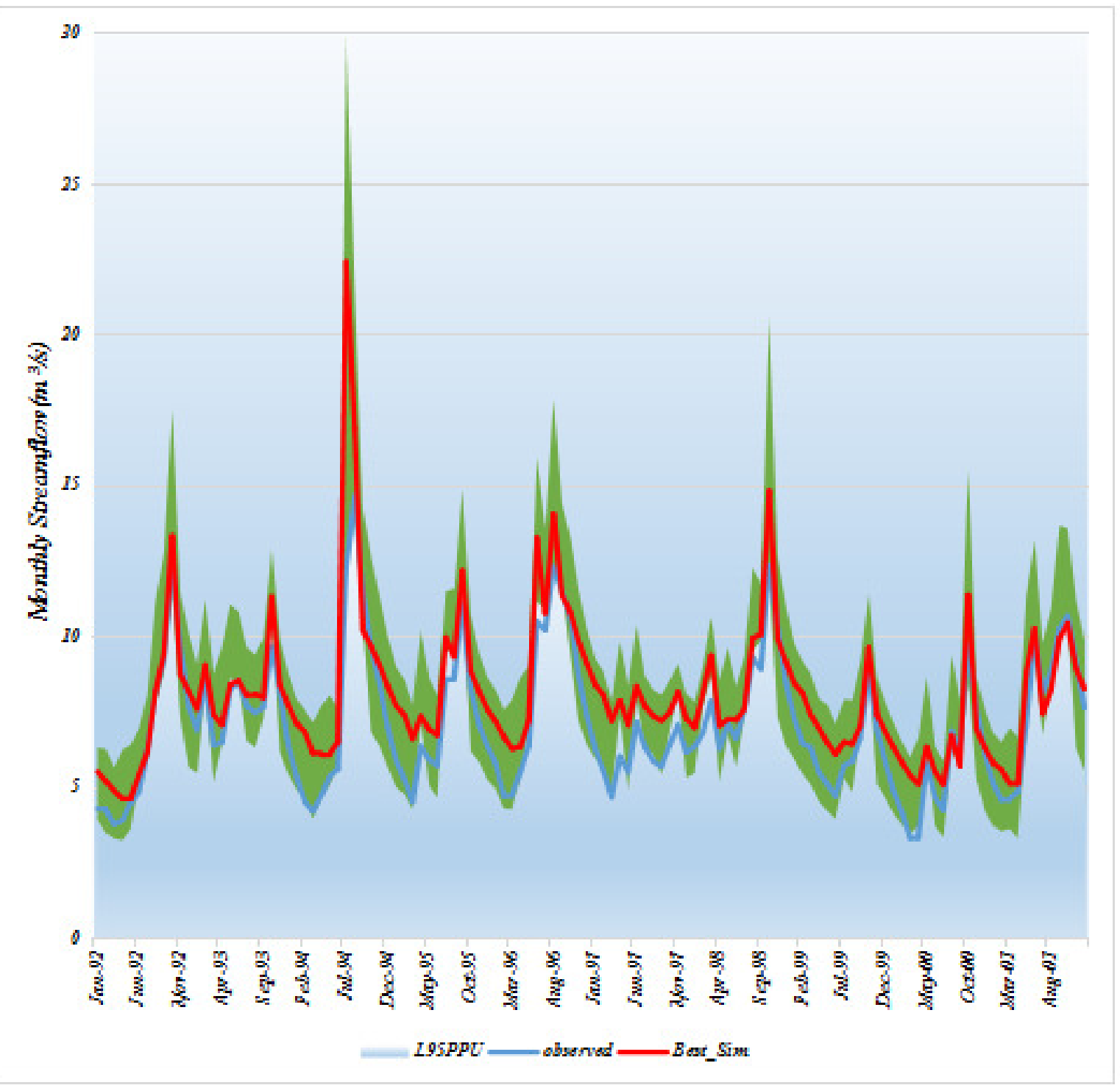

Figure 5. Observed and simulated monthly flow hydrograph during calibration (1992-2001) 


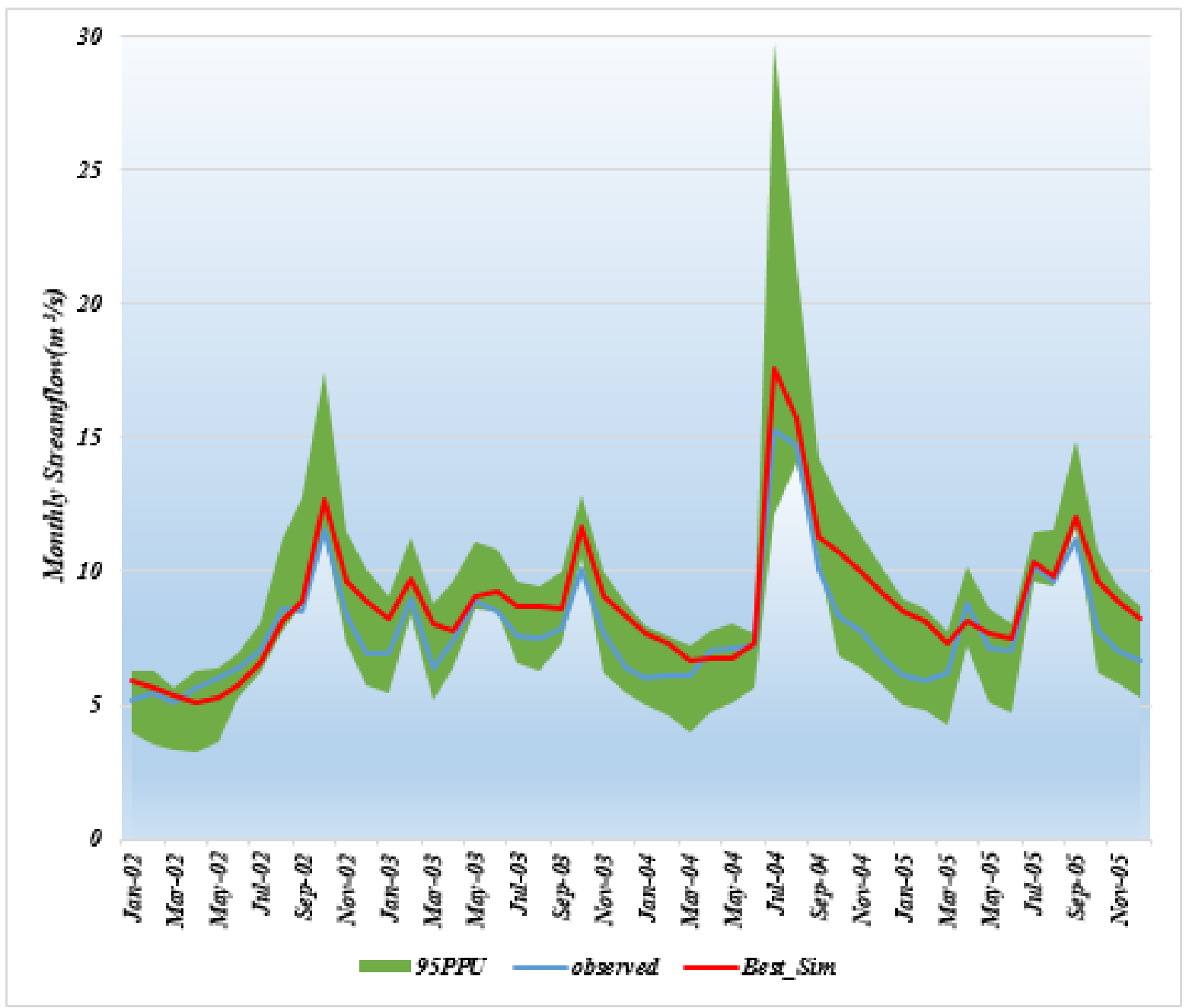

Figure 6. Simulated and observed monthly discharge at the bridge during validation (2002-2005) 


$$
120
$$

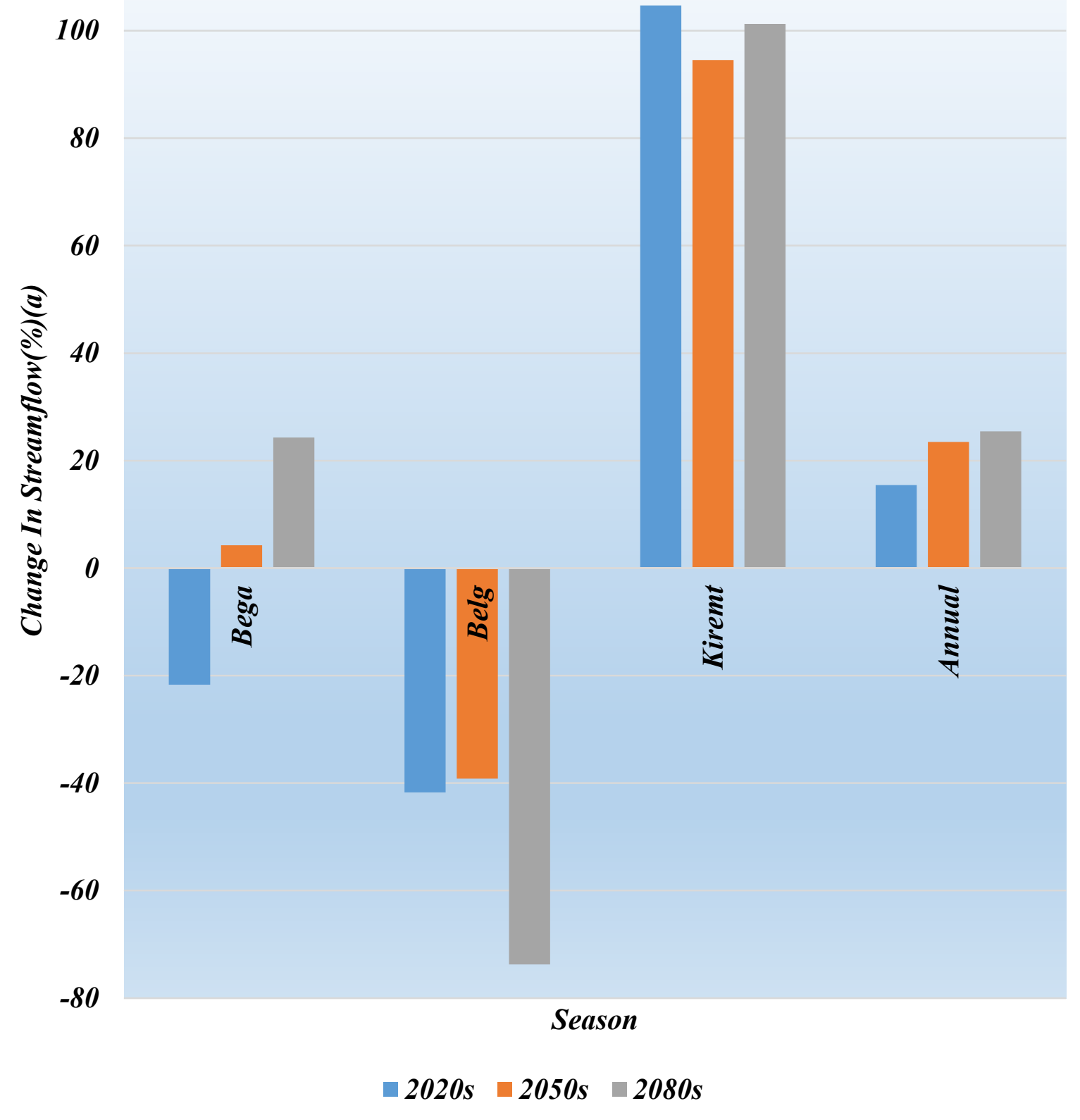




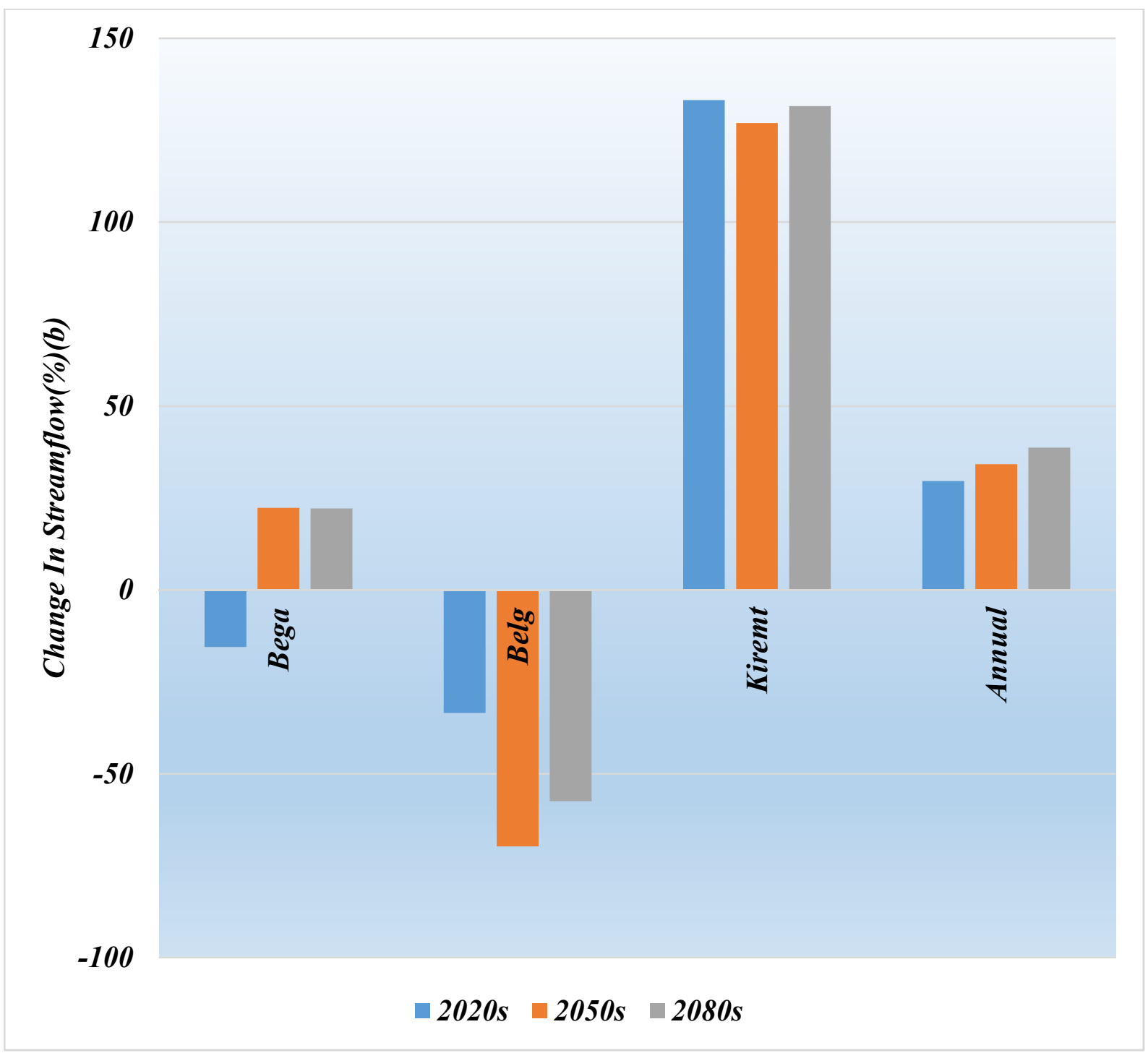

Figure 8. Percentage change in seasonal and annual streamflow for ; (a) RCP 4.5 and (b) RCP 8.5 scenario 


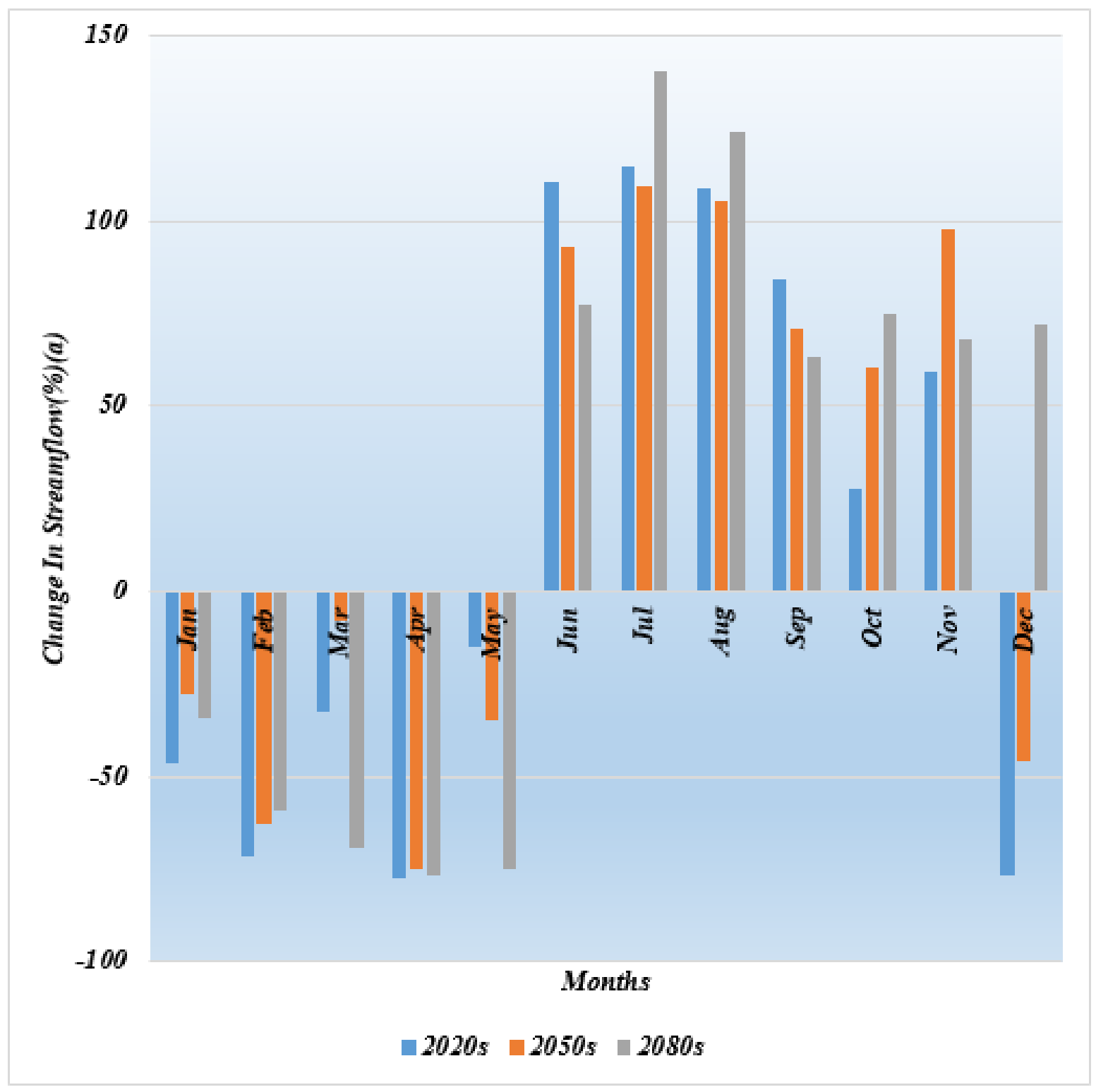




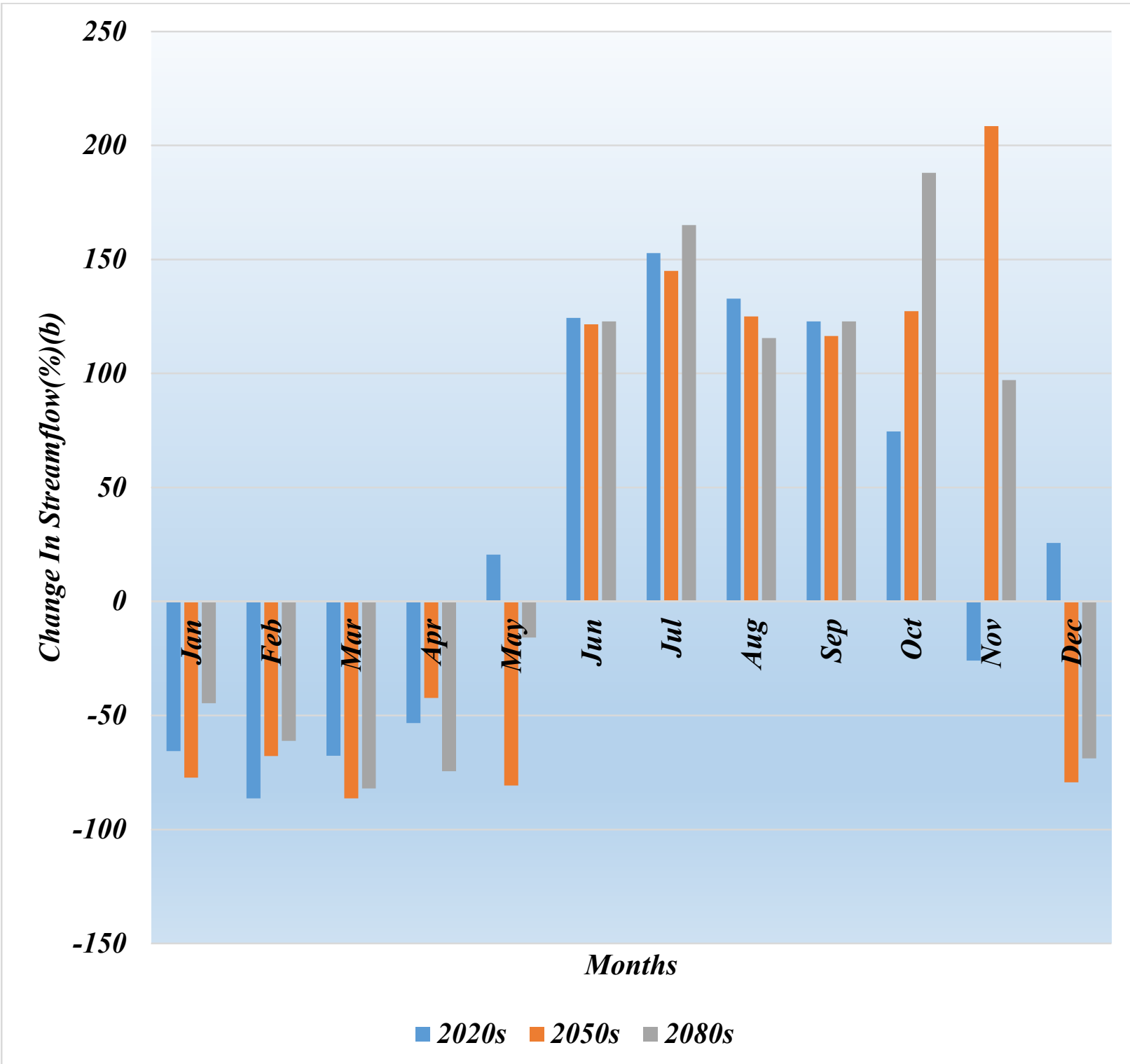

Figure 7. Monthly percentage change in streamflow for both (a) RCP 4.5 and (b) RCP 8.5 scenario 